\title{
EDUCAÇÃO E SAÚDE: ATIVIDADE EDUCATIVA NA ESCOLA AUGUSTO GOTARDELO EM JUIZ DE FORA, MG
}

\author{
Sheila Aparecida Teixeira ${ }^{1}$ \\ Anna Paula Nogueira Pereira ${ }^{2}$ \\ Thalita Jhennyfer Rodrigues ${ }^{3}$ \\ Vivian de Souza Marliere ${ }^{4}$ \\ Ana Claudia Peres Rodrigues ${ }^{5}$
}

\begin{abstract}
RESUMO: O objetivo do trabalho foi desenvolver atividades de promoção da saúde em uma escola municipal de ensino fundamental. A metodologia utilizada foi a realização de oficinas lúdicas e interativas para os alunos do $2^{\circ}, 3^{\circ}, 4^{\circ}$ e $5^{\circ}$ anos do ensino fundamental. Os temas das oficinas foram: alimentação saudável, parasitose e higiene corporal. Além das oficinas realizadas em salas de aulas foram desenvolvidas atividades em um sábado letivo, que envolveu oficinas educativas com as crianças, e, com os pais, uma atividade denominada "café com papo", em que os temas, sugeridos pela escola, foram abordados por meio de vídeos, palestras e discussões. Ocorreu, também, a construção de um jornal denominado "Jornal da Saúde". Estas atividades apresentaram resultados positivos, demonstrados pelos depoimentos das crianças, pais e funcionários da escola. Como conclusão, é possível ressaltar a validade desta iniciativa de trabalhar com a promoção da saúde no espaço escolar. A escola é um ambiente propício para a aplicação de atividades de educação em saúde, pois a mesma está inserida em todas as dimensões do aprendizado.
\end{abstract}

PALAVRAS-CHAVE: Saúde na escola. Promoção da saúde. Educação nutricional.

\section{Education and health: educational activity in school Augusto Gotardelo in Juiz de Fora, MG}

\begin{abstract}
The aim of this paper was to develop health promotion activities in a municipal elementary school. The methodology used was the accomplishment of playful and interactive workshops for students of the 2nd, 3rd, 4th and 5th grade of elementary school. The workshops themes were a healthy diet, parasites and personal hygiene. In addition to the workshops, classroom activities have been also themes on Saturdays academic, involving educational workshops with children and parents, an activity called "coffee chat" where the themes suggested by the school have been addressed through videos, lectures and discussions. There was also the development of a newspaper known as the newspaper health. These activities had positive results shown by the testimony of children, parents and school staff. In conclusion, it is possible to emphasize the validity of this initiative in working with health promotion in the school. The school is an environment for the implementation of activities in health education, because it is embedded in all dimensions off earning.

\footnotetext{
Acadêmica do curso de Nutrição da Universidade Federal de Juiz de Fora, bolsista de extensão do projeto "Educação Nutricional para Promoção da Saúde" (s_ateixeira@yahoo.com.br). para Promoção da Saúde" (annapaulanogueirapereira@yahoo.com.br).

3 Acadêmica do curso de Nutrição da Universidade Federal de Juiz de Fora, bolsista de apoio estudantil do projeto "Educação Nutricional para Promoção da Saúde", (thalitajhennyferrodrigues@hotmail.com).

${ }^{4}$ Acadêmica do curso de Serviço Social da Universidade Federal de Juiz de Fora, bolsista de apoio estudantil do projeto "Educação Nutricional para Promoção da Saúde" (vivimarliere@hotmail.com).

5 Doutora em Zootecnia pela Universidade Federal de Viçosa, professora associada no Instituto de Ciências Biológicas da Universidade Federal de Juiz de Fora, coordenadora do projeto de extensão "Educação Nutricional para Promoção da Saúde" (ana.rodrigues@ufjf.edu.br).

${ }^{2}$ Acadêmica do curso de Enfermagem da Universidade Federal de Juiz de Fora, bolsista de apoio estudantil do projeto "Educação Nutricional
\end{abstract}


KEYWORDS: Health in the school. Health promotion. Nutrition education.

\section{INTRODUÇÃO}

O presente trabalho relata uma experiência de intervenção para promoção da saúde em uma escola de ensino fundamental de um bairro no entorno da Universidade Federal de Juiz de Fora. Durante o projeto, atividades educativas foram aplicadas com as crianças e seus pais, o que permitiu criar um espaço de diálogo sobre os temas abordados.

As atividades em questão foram realizadas por um conjunto de alunos dos cursos de graduação de Enfermagem, Nutrição e Serviço Social, participantes do projeto de extensão "Educação para promoção da saúde", cadastrado na Pró-Reitoria de Extensão da Universidade Federal de Juiz de Fora.

Considerando que a extensão se coloca como espaço estratégico para a articulação das diversas atividades acadêmicas, tais como a integração do ensino, pesquisa, extensão e a interdisciplinaridade, o trabalho da equipe extensionista permite o relacionamento da comunidade universitária e a comunidade extramuros, possibilitando a efetiva participação de atores externos à Universidade. Sendo a extensão universitária um processo educativo, esta interação entre a instituição de ensino superior e comunidade externa possibilita o desenvolvimento da interação entre o saber popular e científico, principalmente quando as metodologias participativas são empregadas (THIOLLENT et al., 2003).

A escolha do ambiente para o desenvolvimento das atividades educativas fundamentou-se na visão de que a escola é um espaço propício para o desenvolvimento de uma análise crítica e reflexiva de valores, comportamentos, condições sociais e modos de vida que objetivam fortalecer fatores que beneficiem a saúde e o desenvolvimento humano, além de ajudar os membros da comunidade escolar a tomar decisões para promover a própria saúde e a dos demais (IPPOLITO-SHEPHERDS, 2002).

Esta visão é compartilhada por vários autores, que, em seus trabalhos, reforçam o entendimento de que a promoção da saúde deve levar em conta o conhecimento de cada um e propiciar o desenvolvimento de habilidades que permitam a incorporação de atitudes e/ou comportamentos adequados à melhoria da qualidade de vida (PORTUGAL, 2006; DEMARZO; AQUILANTE, 2008).

Diante do exposto, foi desenvolvido este projeto, cuja aplicação ocorreria na Escola Municipal Augusto Gotardelo. A iniciativa fundamentou-se em uma visão integral e no enfoque multidisciplinar, que considera as pessoas no contexto de sua vida cotidiana, na família, na comunidade e na sociedade; e voltou-se para questões relativas à promoção da saúde, envolvendo alimentação, cuidados com o corpo e atividade física, que são temas sempre questionados pela população.

O projeto teve como objetivos realizar atividades educativas sobre saúde, alimentação e nutrição, no cotidiano escolar, e capacitar os graduandos para o desenvolvimento comunitário, estimulando uma postura cidadã dos mesmos. 


\section{METODOLOGIA}

As atividades foram realizadas no período de março de 2010 a abril de 2011 na Escola Municipal Augusto Gotardelo, localizada no bairro Caiçaras, próximo à Universidade Federal de Juiz de Fora (UFJF). A escola possui 350 crianças regularmente matriculadas no Ensino Fundamental.

O projeto foi submetido ao Comitê de Ética da UFJF e aprovado com protocolo número CEP/ HU: 348.033.2004-GRUPOIII. O trabalho de campo foi realizado por acadêmicos dos cursos de graduação em Nutrição, Enfermagem e Serviço Social da UFJF.

A primeira etapa do trabalho foi o planejamento das ações em conjunto com os profissionais da escola. Todas as atividades foram expostas e discutidas em encontros quinzenais com os membros do projeto. Durante a execução do projeto, ocorreu um total de seis oficinas lúdicas e interativas para os alunos do $2^{\circ}, 3^{\circ}, 4^{\circ}$ e $5^{\circ}$ anos do Ensino Fundamental, cujas atividades eram realizadas em sábados letivos, englobando também a construção de um jornal como resultado do projeto em questão. A escolha dos temas que foram apresentados na escola foi feita a partir de reuniões periódicas com os membros do projeto, a diretora da escola e representante dos professores e dos pais e/ou responsáveis, baseando-se em reflexões e demandas da comunidade.

Durante todo o período de intervenção, os acadêmicos participantes trabalharam em conjunto com a coordenadora do projeto, buscando, primeiro, os fundamentos teóricos que permitissem uma discussão sobre a sua atuação na promoção de saúde em cenários de prática diferenciados, principalmente em ambientes escolares. Os alunos foram orientados a produzir um diário de campo de todas as seis oficinas aplicadas na escola, descrevendo as atividades realizadas e a sua percepção do envolvimento das crianças nas atividades propostas. Foi a partir desse material que este relato foi produzido.

A estimativa da participação das crianças nas atividades propostas foi realizada de maneira subjetiva, observando o grau de interação e entusiasmo nas atividades realizadas. Já a avaliação das oficinas pela equipe da escola (diretora e professores) foi feita por meio de questionário com perguntas sobre a percepção do projeto na escola, o efeito das atividades na vivência dos alunos e a importância da parceria da escola com a Universidade. O questionário ficou sob a responsabilidade dos acadêmicos, respondido em conversa com a diretora, professores e um representante dos pais.

A atividade do último sábado letivo foi avaliada pelos pais presentes na mesma, totalizando 35 participantes. A avaliação foi feita por meio de um questionário. Primeiramente, para avaliar a apresentação, perguntou-se a opinião do participante sobre o tema tratado. Neste quesito, 17 pais marcaram a opção "bom", 14 a "ótimo" e quatro, a "ruim". Para analisar o projeto como um todo, foi pesquisado sobre as atividades realizadas com os alunos na escola. O resultado foi que 22 assinalaram a opção "ótimo", 10 a "bom" e três a "ruim". Foi solicitado, ainda, que os pais fizessem sugestões, por escrito, sobre o projeto. Dentre os 35 participantes, 24 fizeram propostas. Em todas as escritas, o projeto foi elogiado, ressaltando a importância das atividades no desenvolvimento das crianças. A grande maioria ofereceu sugestão sobre temas a serem abordados. 
Aoficina sobre alimentação saudável consistiu-se de dois momentos: uma parte teórica, na qual foram abordados os conceitos básicos sobre carboidratos, proteínas, lipídios, vitaminas e sais minerais e a importância da ingestão dos mesmos; e uma parte prática, em que foi solicitado aos alunos que simulassem uma compra no supermercado, "comprando" réplicas de alimentos e analisando, posteriormente, esta compra em relação ao conceito de alimentação saudável. Foi elaborada, também, a montagem de uma pirâmide alimentar, contendo os alimentos básicos e mais consumidos.

A oficina sobre parasitose se desenvolveu da seguinte forma: primeiramente, ocorreu a apresentação de um vídeo preparado pela equipe do projeto, mostrando as características dos parasitas, como o ciclo de vida, manifestações clínicas e formas de transmissão; na segunda parte, foram disponibilizados microscópios para que os alunos pudessem fazer as observações sobre o parasito, possibilitando o reforço do conteúdo passado verbalmente. Aliado a isso, foi chamada a atenção sobre a maneira de preparar e selecionar os alimentos, bem como a forma correta de lavar as mãos, já que essas medidas simples são atitudes efetivas de prevenção de parasitoses.

$\mathrm{Na}$ oficina sobre o tema higiene corporal, tratou-se sobre a importância de se tomar banho corretamente, lavar as mãos, escovar os dentes, ter cuidados com as unhas e roupas.

A dinâmica do último sábado letivo envolveu oficinas educativas com as crianças, realizadas de forma lúdica, utilizando teatro, dança, música, brincadeiras de roda, recortes, colagem e gincanas. Os temas abordados foram o corpo humano, prevenção de acidentes, higiene e cuidado corporal, saúde e ambiente saudável. Ao término das atividades, foi fornecido às crianças um lanche comunitário. Com os pais, foi aplicada uma atividade denominada "café com papo", na qual os temas sugeridos pela escola foram abordados por meio de vídeos, palestras e discussões.

A equipe do projeto também desenvolveu um jornal, denominado "Jornal da Saúde", no qual todas as atividades realizadas foram retratadas, juntamente com entrevistas de pais, alunos e funcionários da escola. $\mathrm{O}$ material foi distribuído entre alunos e funcionários da própria escola.

\section{RESULTADOS E DISCUSSÃO}

Ao final da jornada das atividades educativas, foi possível avaliar, a partir de questionamentos, que as crianças haviam assimilado os conteúdos teóricos discutidos nas oficinas. Em todas as nossas atividades, obtivemos êxito. A afirmação é baseada no fato de que, em todos os retornos à escola, pudemos perceber que a nossa mensagem foi captada pelos alunos, uma vez que, sempre que perguntávamos algo sobre um tema já abordado anteriormente, as respostas corretas eram imediatas.

Enfim, o projeto contribuiu bastante para nossa criatividade, pois pudemos colocar em prática habilidades de apresentação, trabalho em equipe, criação e execução de paródias e teatros, principalmente pela flexibilidade de ideias que o grupo todo possui.

Em relação à avaliação dos pais sobre o projeto, observou-se a satisfação e importância que os mesmo deram ao trabalho realizado com seus filhos. $\mathrm{O}$ fato pode ser visto tanto pelas conversas quanto 
pelas respostas do questionário aplicado no final das atividades realizadas, como descrito abaixo:

A parceria é ótima. Uma das melhores coisas que acontecem aqui na escola. Os alunos assimilam melhor o conhecimento passado nas oficinas mais do quando passado por nós pais.

É muito importante que esses temas sejam passados aos alunos. Minha filha de cinco anos já quer comer cenoura, batata, couve e pede para ter em casa. Acho muito bom este acontecimento, pois tem muita criança que ainda não tem acesso a algumas coisas que são muito importantes.

Durante estas conversas muitos pais sugeriram temas e formas de apresentação:

Uma boa sugestão é falar sobre dentes.

Gostaria de saber mais sobre enxaquecas e pressão alta e diabetes. Quando for falar, falar com palavras que todos entendem e não com palavras difíceis.

Brincadeiras educativas em relação ao que foi mostrado no vídeo, montar uma peça teatral com o assunto. E continuar com o propósito deste projeto.

Os integrantes da escola, professores e diretora, entendem o projeto como um aliado à proposta metodológica. Em suas falas, observamos que eles percebem o auxílio oferecido aos alunos em relação ao desenvolvimento de habilidades, reconhecendo que as atividades são baseadas na descoberta espontânea dos discentes e em uma aprendizagem significativa (HERNANDEZ; VENTURA, 1998).

Depoimento professora responsável pelo $2^{\circ}$ Ano:

A parceria com a UFJF é excelente, pois a nossa comunidade é muito carente e só nós professores não conseguimos suprir todas as necessidades deles [...]. Eu sempre fui a favor da universidade atuar além dos seus portões, pois é fora deles que o aluno realmente aprende.

Depoimento professora responsável pelo $3^{\circ}$ Ano:

Às vezes pensamos que os alunos não são capazes de assimilar todos os conteúdos, mas na realidade eles assimilam sim, pois em aulas teóricas eles reproduzem o conhecimento adquirido nas oficinas.

Depoimento da diretora:

Acredito que o projeto além de enriquecer e contribuir com as atividades desenvolvidas pela escola, também representam uma forma de aproximar a Universidade da realidade social.

Esta experiência mostrou-se uma importante ferramenta para motivar a comunidade escolar em questões relacionadas à promoção da saúde em busca da autonomia e valorização dos conhecimentos no resgate da autoestima dos envolvidos e da importância da valorização do autocuidado. 
Para os discentes, a trajetória deste projeto de extensão revelou-se um aprendizado de solidariedade, trabalho em equipe e participação comunitária. Os alunos perceberam a importância de estimular e envolver a comunidade em novas ações que promovam a saúde. Como forma de continuidade do projeto, os alunos propuseram uma nova forma de intervenção: além das atividades educativas na escola, realizar visitas domiciliares às famílias das crianças.

\section{CONSIDERAÇÕES FINAIS}

Como conclusão, é possível ressaltar a relevância da iniciativa de trabalhar com a promoção da saúde no espaço escolar. Destacamos que, com a realização desse projeto, foi possível manter vínculo e estabelecer parcerias com a comunidade no sentido de conhecer os seus problemas de saúde e buscar formas conjuntas de minimizá-los, auxiliando na promoção de uma melhor qualidade de vida da população local.

\section{REFERÊNCIAS}

DEMARZO, M. M. P.; AQUILANTE, A. G. Saúde escolar e escolas promotoras de saúde. In: Programa de Atualização em Medicina de Família e Comunidade. Porto Alegre: Artmed: Pan-Americana, v. 3, p. 49-76, 2008.

HERNANDEZ, F.; VENTURA, M. A organização do currículo por projetos de trabalho. Porto Alegre: Art Med, 1998.

IPPOLITO-SHEPHERD, J. 2002. Plan de Acción 2003-2012 - Iniciativa Regional Escuelas Promotoras de la Salud. In: Memórias III Reunión Latinoamericana de Escuelas Promotoras de la Salud, Quito: OPAS.

PORTUGAL. Ministério da Saúde. Despacho n ${ }^{0} 12.045$ de 7 de junho de 2006. Diário da República, [S.1.], n. 110, 7 jun. 2006. Programa Nacional de Saúde Escolar.

THIOLLENT, M. et al. (Org.) A extensão universitária: conceitos, métodos e práticas. Rio de Janeiro: Universidade Federal do Rio de Janeiro: Sub-Reitoria de Desenvolvimento e Extensão, Rio de Janeiro, 2003.

Submetido em 26 de junho de 2012.

Aprovado em 27 de agosto de 2012. 